\title{
Sound Absorption Properties of Polyurethane Foams Derived From Waste Cooking Oil Incorporated With Waste Wood Fiber Filler
}

\section{Shafiq M. Azahari, Anika Zafiah M. Rus, M. Taufiq Zaliran, Shaharuddin Kormin}

Sustainable Polymer Engineering, Advanced Manufacturing and Material Center (SPEN-AMMC),

Faculty of Mechanical and Manufacturing Engineering,

Universiti Tun Hussein Onn Malaysia,

86400 Parit Raja, Batu Pahat, Johor, Malaysia.

E-mail: zafiah@uthm.edu.my

Correspondence Author: Anika Zafiah M. Rus, Sustainable Polymer Engineering, Advanced Manufacturing and Material Center (SPEN-AMMC), Faculty of Mechanical and Manufacturing Engineering, Universiti Tun Hussein Onn Malaysia, 86400 Parit Raja, Batu Pahat, Johor, Malaysia.

Received date: 22 December 2017, Accepted date: 22 January 2018, Online date: 5 February 2018

Copyright: (C) 2018 Anika Zafiah M. Rus et al. This is an open-access article distributed under the terms of the Creative Commons Attribution License, which permits unrestricted use, distribution, and reproduction in any medium, provided the original author and source are credited.

\begin{abstract}
Polymeric foams and its composites are known as an acoustic material with absorption properties that play an important role in reducing the noise level. The sound absorption properties of polyurethane foam (PU) produced from waste cooking oil polyol (WCOs) incorporated with Red Meranti fiber is conducted to measured its outstanding performance. This paper comprises an experimental study on acoustic properties using an Impedance Tube test of polyurethane closed-cell foam, by incorporating various quantities of waste Red Meranti fiber into the PU matrix. The results revealed the presence of the Red Meranti filler has a major influence on the structure and acoustical properties of the foams. The highest fiber filler percentage loading decreased the pore size of the foams which subsequently influenced the sound absorption coefficients, $\alpha$. Thus, PU ${ }_{20}$ with the smallest pore diameter of $653.8 \mu \mathrm{m}$ contributed highest $\alpha$ value of 0.9888 . Evidently, the foam composite obtained have better sound absorption properties compared to PU.
\end{abstract}

Key words: Renewable Polymer, Waste cooking oil, Polyol, Red Meranti, Sound absorption coefficient.

\section{INTRODUCTION}

Biomass, vegetable oils or industrial by-products have been utilized to substitute petroleum-based polyols in the synthesis of polyurethane foam (PU) to reduce the dependency on petroleum feedstocks $[1,10]$. Without a doubt, the substitution of petroleum feedstocks by renewable resources has been receiving extensive consideration for quite a while. The attention on natural biomass feedstock is also on the conversion process into monomer, polymers, and composites Several works have also been investigated with respect to the production of polyols for the PU industry which included the acid liquefaction of identified biomass residues $[6,1,11]$.

The production of PU from Waste Cooking Oil (WCOs) might also help to lessen the current WCOs excess and to enhance the sustainability of the PU industry. The production of PU by using WCOs and biomass polyols also still alluring as the lower level of purity required for PU production keeps the cost competitive.

A byproduct of the biodiesel production has received much consideration $[6,12,16]$ which importantly have been led to produce both chemical and biological processes to convert waste oils into value-added products. However, the effective substitution of petrochemicals by WCOs and/or biomass polyols in the PU production can possibly reduce their cost and ecological effect.

Foams produced from renewable resources are generally rigid because of the small chain length of the polyols, the presence of rigid groups such as aromatic rings also adds to their stiffness and high crosslinking density related with high performance. Hence, this kind of materials is commonly used in thermal insulation and as structural materials [18] Nevertheless, in spite of their porous structure, their use as sound absorbers has not received much consideration when compared to flexible foams. The last is known to have great sound absorption properties due to the channels, interstices, or cavities exhibit in their structure.

Rigid PU commonly comprises a combination of open, partially open (closed cells with small pinholes) or fully closed cells and a combination of all of them. Therefore, sufficient understanding of the relationship between the acoustical properties, the porous structure, and the sound absorption performance is required when using the rigid foams as sound absorbing materials [21]. Moreover, in these works, the uses of the fiber fillers are important for the sound absorption properties. This is due to its biodegradable, cheaper, eco-friendly, availability, good acoustic insulating [2,15], while, PU synthesized from WCOs have huge potential in the areas where damping properties can be highlighted as an added value [13].

Considering the potential of PU from WCOs and Red Meranti mentioned above, this work of PU derived from WCOs monomer incorporated with Red Meranti fiber filler were prepared. The relationship between their structure and acoustical properties with their sound absorption capability is discussed.

Methodology:

Raw materials and Fabrication of PU foam and its composites:

The PU foams were produced by the reaction of WCOs polyols (monomer) with isocyanate in the presence of a Red Meranti fiber [1,10,16,2]. WCOs monomer and Red Meranti $(<300 \mu \mathrm{m})$ fiber filler were homogeneously mixed using a stirrer and crosslinker were added to the monomer with certain ratio of 1:0.5 
(wt/wt of monomer). The fiber filler were mixed by following the ratio of 5, 10, 15 and $20 \mathrm{wt} / \mathrm{wt} \%$ of WCOs monomer. The mixture were left to cure and rise at room temperature for 24 hours $[3,16,2]$ and namely as $\mathrm{PU}, \mathrm{PU}_{5}, \mathrm{PU}_{10}, \mathrm{PU}_{15}$, and $\mathrm{PU}_{20}$ respectively.

The foams were prepared in a cylindrical shape with a diameter $100 \mathrm{~mm}$ and $28 \mathrm{~mm}$ as shown in Figure 1. The PU formulation is tabulated in Table 1.

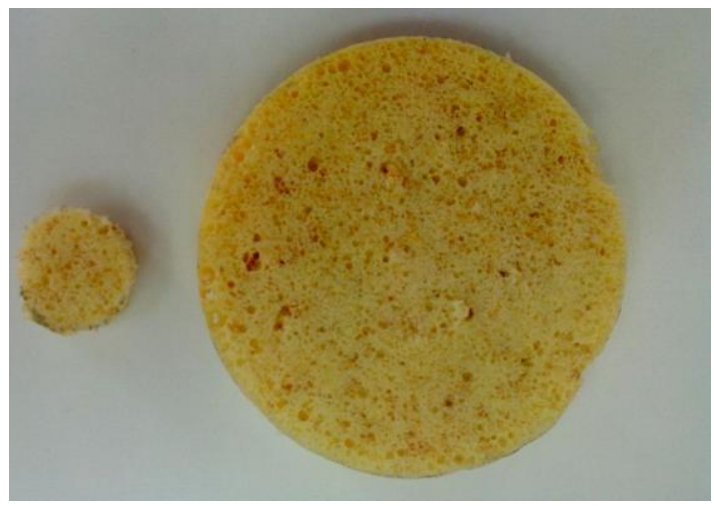

Fig. 1: PU foam samples with interconnected open pore structure for Impedance Tube test.

Table 1: Foam formulations

\begin{tabular}{|l|l|l|l|}
\hline Sample & Polyols, WCOs $(\mathrm{g})$ & $\begin{array}{l}\text { Crosslinker } \\
(\mathrm{g})\end{array}$ & Red Meranti fiber filler $(\mathrm{g})$ \\
\hline $\mathrm{PU}$ & 30 & 15 & 0 \\
\hline $\mathrm{PU}_{5}$ & 30 & 15 & 1.5 \\
\hline $\mathrm{PU}_{10}$ & 30 & 15 & 3.0 \\
\hline $\mathrm{PU}_{15}$ & 30 & 15 & 4.5 \\
\hline $\mathrm{PU}_{20}$ & 30 & 15 & 6.0 \\
\hline
\end{tabular}

Characterization of $P U$ and its composites:

Scanning Electron Microscopy (SEM) analyses were performed in a JEOL-JSM6380LA for foams after vacuum-coating with gold (Auto Fined Coater of JEOL-JFC1600) to avoid electrostatic charging during testing and at accelerating voltage of $10.0 \mathrm{kV}$ [16,2]. Interconnected pore diameter was obtained by measuring at least 10 interconnected pore diameter on the surface of each foam.

The sound absorption coefficient values were determined to measure the minimum (Ln, Min.) and maximum (Ln, Max.) sound pressure levels in a horizontal wave tube at different frequencies according to ASTM E1050. The sound absorption coefficient value was calculated as the average value of three cylindrical foam pieces with $10 \mathrm{~mm}$ thick and $100 \mathrm{~mm}$ (high frequency) and $28 \mathrm{~mm}$ (low frequency) in diameter, over the frequency range of $0-5000 \mathrm{~Hz}$ [2,16,3]. For the interpretation of the sound absorption efficiency, the noise reduction coefficient (NRC, arithmetic mean of absorption coefficients at 200, 500, 1000, and 2000 Hz) was calculated $[5,17]$.

\section{Results:}

PUs is commonly used as sound absorbing materials and the suitability of renewable feedstocks (WCOs polyols from biomass) for the production of foams has been reported [18,4]. In the present studies, the relationship between the porosity of PU derived from WCOs incorporated with Red Meranti fiber with their sound absorption coefficient values is discussed.

\section{Morphological structure of $P U$ and its composites:}

The morphological cell structure of the foams is observed in Figure 2. The cross-section morphology of (a) PU, (b) $\mathrm{PU}_{5}$, (c) $\mathrm{PU}_{10}$, (d) $\mathrm{PU}_{15}$, and (e) $\mathrm{PU}_{20}$ are presented. The interconnected pore size diameter of different composition ratio of fiber filler foams is illustrated in Figure 3 . $\mathrm{PU}_{20}$ revealed the morphology of interconnected open cell structure with the smallest average pore diameter of $444.6 \mu \mathrm{m}$. In contrast, PU which has been prepared using only the polyol derived from WCOs, have the calculated average pore diameter of $653.8 \mu \mathrm{m}$. The differences of the interconnected morphology pore size diameter can be related to the weight percentage composition of the fiber filler used in the polymer matrix. As the percentage of the fiber filler increased, the pore size diameter will be decreased.

Viscosity of the mixture increases as the percentage loading of the fillers increases which contradict to the formation of the pores. Therefore, the reduction in pore size is in consistent with further increments of the filler percentage loading. The fibres fillers turn as defects in the matrix as well as it might attribute to the agglomeration of fillers in the matrix at high percentage loading of filler [19].

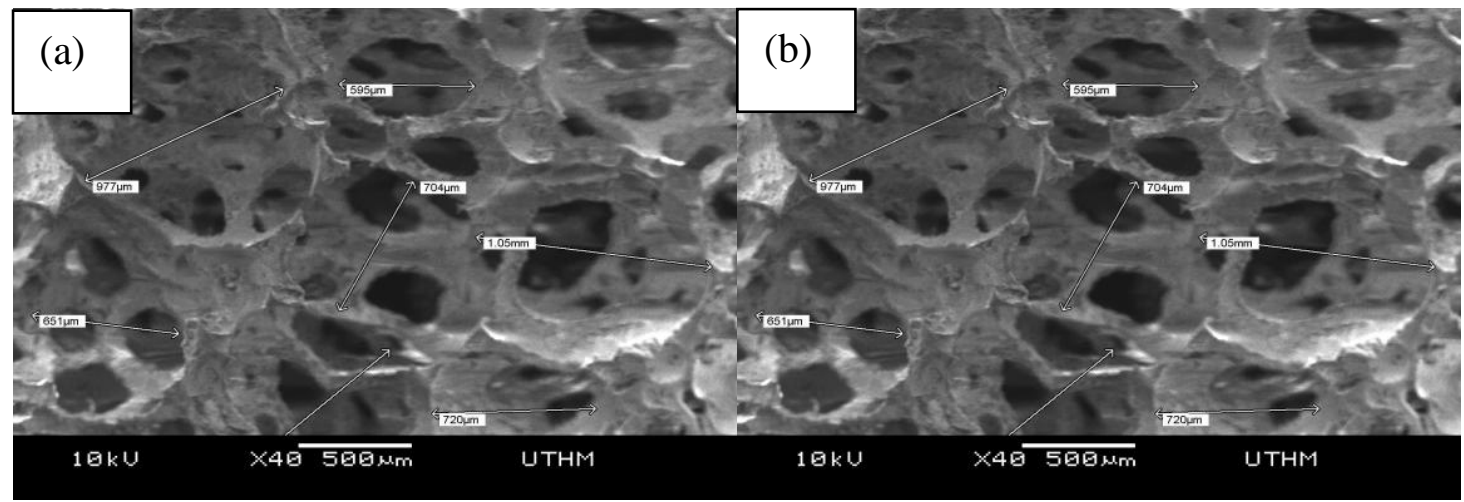



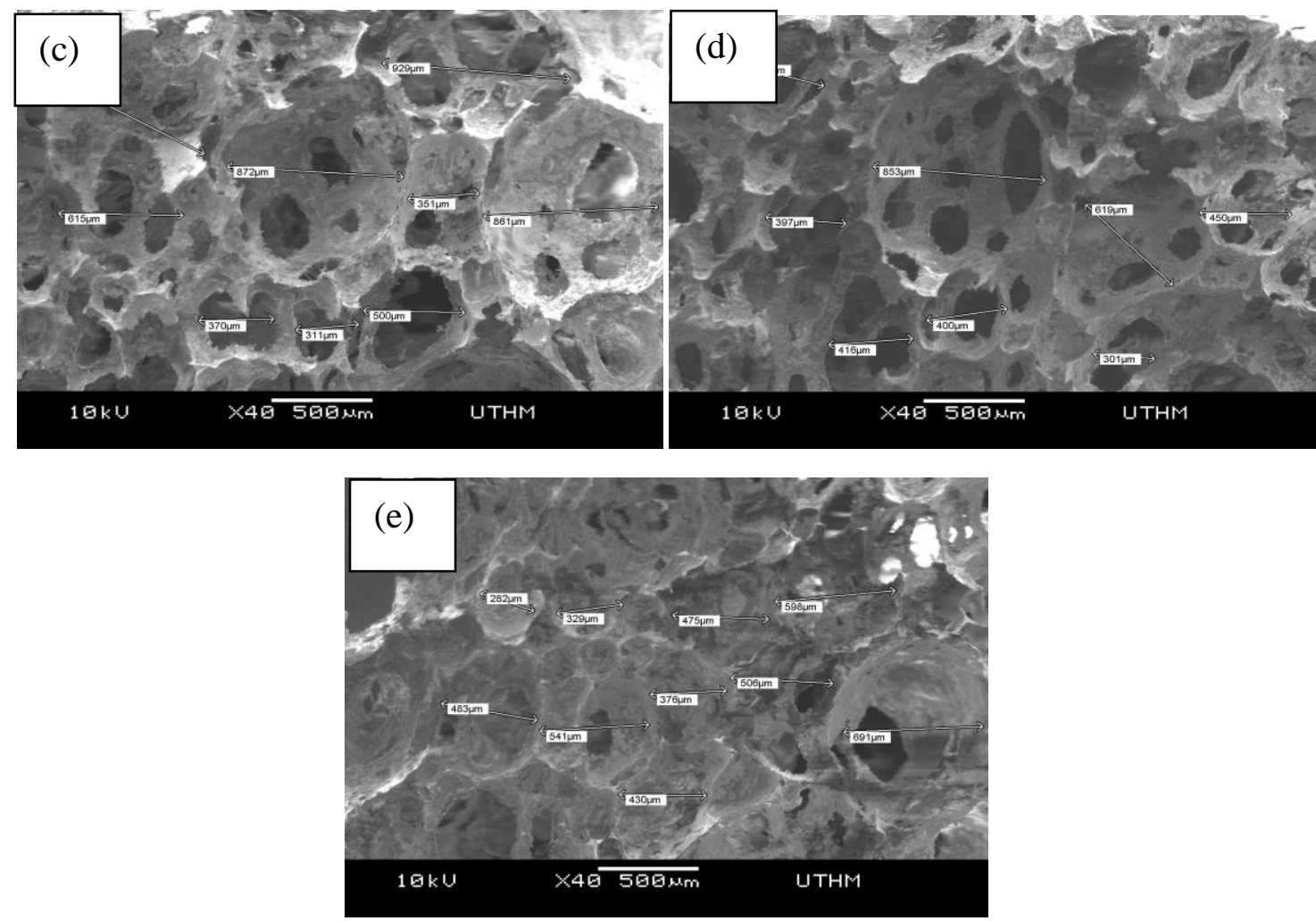

Fig. 2: Micrograph of the cross-section surface of (a) $\mathrm{PU}$, (b) $\mathrm{PU}_{5}$, (c) $\mathrm{PU}_{10}$, (d) $\mathrm{PU}_{15}$ and (e) $\mathrm{PU}_{20}$.

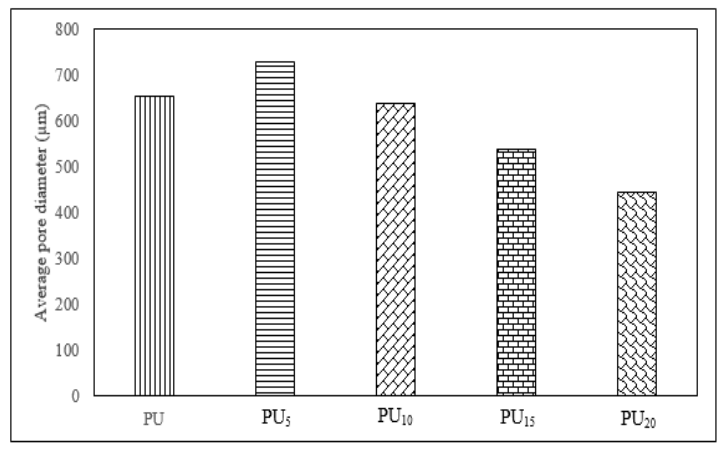

Fig. 3: The average pore diameter of $\mathrm{PU}, \mathrm{PU}_{5}, \mathrm{PU}_{10}, \mathrm{PU}_{15}$, and $\mathrm{PU}_{20}$.

Smaller pore size directly affects the air flow resistivity and collisions of sound waves with struts through vibration and dissipation energy transfers. Furthermore, the stiffness of cell walls influences the absorption efficiency of polyurethane foams. This pore structure variation is strongly related to the sound absorption due to the different energy transfer behaviour of sound waves relying upon the pore structures. Generally, at low and high frequencies, a smaller pore size gives better control of sound absorption [8,9]. Therefore, sound absorption efficiency can be improved by reducing pore size and increasing damping capacity of the foam materials with Red Meranti fillers.

Sound absorption coefficient, $\alpha$ of $P U$ and its composites:

When sound waves hit a surface they can be reflected, absorbed or transmitted [20]. Sound wave in the form of heat energy is produced due to the friction between air flowing in and or out of the cells [21,7]. The efficiency of sound wave absorbers can be evaluated by the sound absorption coefficient, $\alpha$. The sound absorption coefficient values of the prepared PU is determined at frequencies ranging from 0 to $5000 \mathrm{~Hz}$ and plotted in Figure 4 .

The observation of the sound absorption coefficient values is increased but decreasing in the absorption frequency level for all composites samples. Evidently, $\mathrm{PU}_{20}$ has higher sound absorption coefficient values, $\alpha$ which are 0.9888 at lowest frequency absorption level.

This type of pore structure is associated with increased airflow resistivity which improves sound absorption in the whole range of frequencies [14]. In addition, the acoustic properties of this foam may be associated with the presence of Red Meranti in PU which acted as functional fiber fillers with increased absorption coefficients. The fiber filler also influences the damping properties and able to reduce the sound wave energy as a result of the smaller average pore size diameter and more regular pore size and structure. In other hand, due to the higher number of partially opened pores was resulting in the improved $\alpha$ value.

The synergistic mechanisms of wave damping by Red Meranti fillers and wave collisions through the pores also contributed in the improvement of $\alpha$ value. The methods involved in wave dissipation process are firstly, the sound absorption is increased by damping motions of the foams with the Red Meranti fillers, as explained with the effects of movements by Red Meranti fillers when polymer foam recovers from the deformation caused by the sound energy [20]. While, second method is the change in wave penetration pathways whereby the sound absorption was increased due to the pore structures in the foam matrix [7]. The increase of the airflow resistivity improves the absorption behavior in the whole frequency range until some point of pore size, but a too resistive porous material can demonstrates low sound absorption because it would be more difficult for the acoustic wave penetration.

Besides that, the damping motion of Red Meranti fillers, scattering and reflection of sound waves can be happened at the foam walls, thus, increase the sound absorption. The scattering and reflection of sound waves can also lengthening the transmission routes in the foams, and this also causes the increase of the energy loss [14]. In order to receive the potential use of these foams in sound absorption with other foams reported, the noise reduction coefficients (NRC) were calculated and the values are tabulated in Figure 5. 


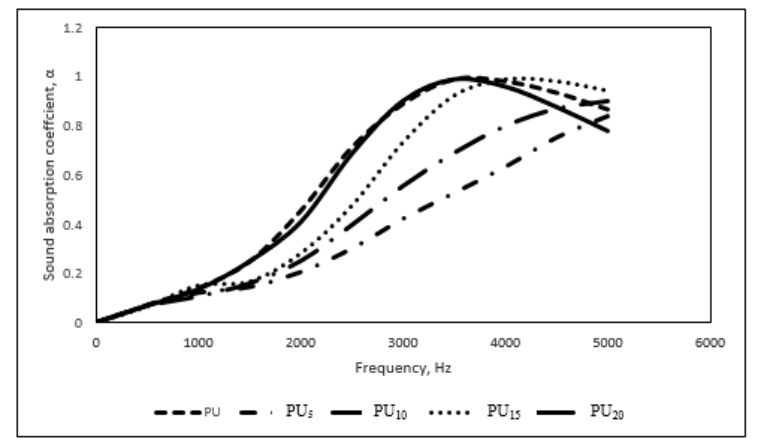

Fig. 4: Sound absorption coefficient values of $\mathrm{PU}, \mathrm{PU}_{5}, \mathrm{PU}_{10}, \mathrm{PU}_{15}$, and $\mathrm{PU}_{20}$.

Figure 5 of the NRC values of the PU foams using polyols derived from WCOs incorporated with Red Meranti fiber filler are gen erally similar to those reported for other materials used as sound absorbers and in some cases higher, indicating that these rigid foams have potential as sound absorbing materials $[10,12]$.

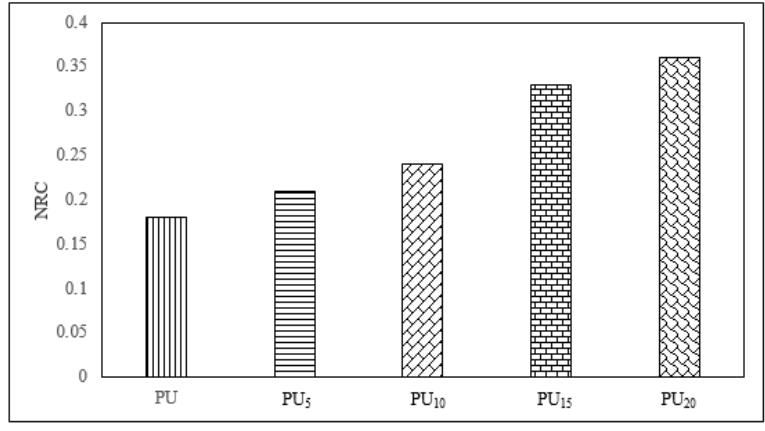

Fig. 5: Noise reduction coefficient (NRC) of samples obtained at frequencies 200,500, 1000, and $2000 \mathrm{~Hz}$.

It can be observed that with the increase of Red Meranti filler percentage, the value of noise reduction coefficient (NRC) also increases. The PU $\mathrm{U}_{20}$ foam has maximum NRC value of 0.36 , which is twice as the PU. Furthermore, incorporation of these polyols with fiber filler and optimization of formulations will support widening the range of frequencies where rigid PU can be used as sound absorbers.

Conclusion:

In the present study, WCOs derived polyol with added Red Meranti fiber were used to produce eco-friendly sound absorbing PU foam. The properties of the foams indicated that the presence of Red Meranti filler on the WCOs derived polyol decreased the pore size which increased the sound absorption coefficient values of the foams at low and high absorption frequencies level. The optimum sound absorption coefficient is 0.9888 with the highest filler content of $\mathrm{PU}_{20}$. While the highest noise reduction coefficient is 0.36 is calculated for $\mathrm{PU}_{20}$.

\section{ACKNOWLEDGEMENTS}

The author would like to thank Sustainable Polymer Engineering, Advanced Manufacturing and Materials Center (SPEN-AMMC), Universiti Tun Hussein Onn Malaysia (UTHM), Johor and Malaysian Government for supporting this research under Postgraduate Incentive Research Grant (GIPS U832), Incentive Grant Scheme (IGSP U678) for publication and Fundamental Research Grant Scheme, vot 1481.

\section{REFERENCES}

[1] Adnan, N.Q.A. and A.Z.M. Rus., 2013. Sound Absorption of Laminated Biopolymer Foam and Epoxy Foam. Key Engineering Materials, 594-595: 291-295.

[2] Azahari, M.S.M., A.Z.M. Rus, M. Taufiq Zaliran and S. Kormin, 2017. Improving sound absorption property of polyurethane foams doped with natural fiber. IOP Conference Series: Materials Science and Engineering, 226: 012009.

[3] Azahari, M.S.M., A.Z.M. Rus, S. Kormin and M.T. Zaliran, 2017. Acoustic properties of polymer foam composites blended with different percentage loadings of natural fiber. IOP Conference Series: Materials Science and Engineering, 244: 012009.

[4] Berardi, U. and G. Iannace, 2015. Acoustic characterization of natural fibers for sound absorption applications. Building and Environment, 94: 840-852.

[5] Chathurangani, O., W. Perera and H. Kumari, 2012. Utilization of Sawdust and Coconut Coir Fibre as Noise Reducing Wall Surface Materials. Civil.Mrt.Ac.Lk, pp: 16-19.

[6] Dang, Y., X. Luo, F. Wang and Y. Li, 2016. Value-added conversion of waste cooking oil and post-consumer PET bottles into biodiesel and polyurethane foams. Waste Management, 52: 360-366.

[7] Doutres, O., N. Atalla, M. Brouillette and C. Hébert, 2014. Using shock waves to improve the sound absorbing efficiency of closed-cell foams. Applied Acoustics, 79: 110-116.

[8] Gwon, J.G., S.K. Kim and J.H. Kim, 2015. Sound absorption behavior of flexible polyurethane foams with distinct cellular structures. Quaternary International, 387: 132.

[9] Gwon, J.G., S.K. Kim and J.H. Kim, 2016. Sound absorption behavior of flexible polyurethane foams with distinct cellular structures. Materials \& Design, 89: 448-454.

[10] Hassan, N.N.M. and A.Z.M. Rus, 2014. Acoustic performance of green polymer foam from renewable resources after UV exposure. International Journal of Automotive and Mechanical Engineering, 9(1): 1639-1648.

[11] Hassan, N.N.M. and A.Z.M. Rus, 2013. Influences of Thickness and Fabric for Sound Absorption of Biopolymer Composite. Applied Mechanics and Materials, 393: 102-107.

[12] Ji, D., Z. Fang, W. He, Z. Luo, X. Jiang, T. Wang and K. Guo, 2015. Polyurethane rigid foams formed from different soy-based polyols by the ring opening of epoxidised soybean oil with methanol, phenol, and cyclohexanol. Industrial Crops and Products, 74: 76-82. 
[13] Jin, W., J. Liu, Z. Wang, Y. Wang, Z. Cao, Y. Liu and X. Zhu, 2015. Sound absorption characteristics of aluminum foams treated by plasma electrolytic oxidation. Materials, 8(11): 7511-7518.

[14] Liu, P.S., H.B. Qing and H.L. Hou, 2015. Primary investigation on sound absorption performance of highly porous titanium foams. Materials and Design, 85: 275-281.

[15] Nordin, M.N.A.A., L.M. Wan, M.H. Zainulabidin and A.S.M. Kassim, 2016. Research finding in natural fibers sound absorbing material., 11(14): 85798584.

[16] Rus, A.Z.M., M.S.M. Azahari, S. Kormin, L.B. Soon, M.T. Zaliran and A.S.M.F. L., 2017. Hybrid waste filler filled bio-polymer foam composites for sound absorbent materials. AIP Conference Proceedings: 1877. 060004: 060004.

[17] Sa'adon, S. and A.Z.M. Rus, 2014. Acoustical behavior of treated wood dust-filler for polymer foam composite. Applied Mechanics and Materials, 465-466: 1039-1043.

[18] Septevani, A. a., D. a C. Evans, C. Chaleat, D.J. Martin and P.K. Annamalai, 2015. A systematic study substituting polyether polyol with palm kernel oil based polyester polyol in rigid polyurethane foam. Industrial Crops and Products, 66: 16-26.

[19] Sung, G., S.K. Kim, J.W. Kim and J.H. Kim, 2016. Effect of isocyanate molecular structures in fabricating flexible polyurethane foams on sound absorption behavior. Polymer Testing, 53: 156-164.

[20] Sung, G. and J.H. Kim, 2017. Influence of filler surface characteristics on morphological, physical, acoustic properties of polyurethane composite foams filled with inorganic fillers. Composites Science and Technology, 146: 147-154.

[21] Zhu, X., B.-J. Kim, Q. Wang and Q. Wu, 2013. Recent Advances in the Sound Insulation Properties of Bio-based Materials. BioResources, 9(1): 1764-1786.

[22] Zieleniewska, M., M.K. Leszczyński, M. Kurańska, A. Prociak, L. Szczepkowski, M. Krzyzowska and J. Ryszkowska, 2015. Preparation and characterisation of rigid polyurethane foams using a rapeseed oil-based polyol. Industrial Crops and Products, 74: 887-897. 